\title{
Mining-Induced Damage Characteristics of Floors during Fully Mechanized Caving Mining: A Case Study
}

\author{
Yulong Jiang, Dongfeng Zhang, Kai Wang, and Xiaoqiang Zhang $\mathbb{C}$ \\ College of Mining Engineering, Taiyuan University of Technology, Taiyuan, Shanxi 030024, China \\ Correspondence should be addressed to Xiaoqiang Zhang; tyzxq2009@163.com
}

Received 20 June 2018; Accepted 1 October 2018; Published 24 October 2018

Academic Editor: Alicia E. Ares

Copyright (c) 2018 Yulong Jiang et al. This is an open access article distributed under the Creative Commons Attribution License, which permits unrestricted use, distribution, and reproduction in any medium, provided the original work is properly cited.

To study the mining-induced damage characteristics of floors during fully mechanized mining, in situ measurements were performed using the hollow inclusion strain sensors in the No. $100502(80 \mathrm{~m}, 180 \mathrm{~m})$ mining face of the Yitang Coal Mine in the Huoxi coal field in the Shanxi Province of China. The in situ measurement results show that the failure depths of the floor rocks in the $100502(80 \mathrm{~m})$ and $100502(180 \mathrm{~m})$ mining faces were $12.50 \sim 14.65 \mathrm{~m}$ and $17.50 \sim 19.20 \mathrm{~m}$, respectively. The longer the mining face was, the greater the failure depth and the more severe the deformation and damage of the floor rocks were. The failures of the damaged floor rocks can be divided into two types: pull-pressure strain mutations and abnormal mutations. With the advancement of the mining face, the strain increments of floor rocks at different buried depths showed obvious advanced and lagged responses. Specifically, the advanced response distance decreased with a negative exponential trend, while the lagged response distance generally first increased and then decreased as the depth increased. The results can not only provide important guidance to coal mining under water pressure, but also offer a key theoretical reference for failure depth control of floor rocks under similar geophysical conditions.

\section{Introduction}

With the increasing demand for energy resources, in recent years, coal mining has gradually moved deeper and deeper, and many potential threats have followed [1-3]. The Ordovician limestone aquifers present in the deep rocks greatly threaten mining safety [4]. According to statistical data, there have been 285 mines affected by Ordovician limestone aquifer hazards in China, with a total amount of 25 billion tons of coal in these mines [5]. When mining under the water pressure of aquifers, preventions in connection with the Ordovician limestone aquifers and damaged coal seam floors are basic insurances to avoid the water-inrush disasters [6]. Therefore, studying the failure of coal seam floor rocks is of great significance for ensuring the safe and efficient mining under the water pressure of aquifers.

Many studies regarding coal seam floor failure have been performed. Based on an improved Hoek-Brown rock strength criterion, Santos and Bieniawski [7] introduced a critical energy-release point to analyze the bearing capacity and stability principles of coal seam floor under long-term conditions. Wang et al. [8] identified that rock fractures when the tensile strain induced by mining actions exceeds the ultimate strain. Assuming rock isotropy, Li and Gao [9] established a damage model to quantitatively describe the crack damage evolution of floor rocks and explored the failure mechanism of floor rocks by mesodamage mechanics. Yin et al. [10] performed field monitoring of the stress states of coal seam floor rocks during the mining process and revealed that the vertical stress increments of the floor rocks decrease exponentially with depth, and the horizontal stress increases linearly with depth. Combining field measurement, theoretical analysis, and numerical simulation, Zhu et al. [11, 12] determined an analytical solution for the support stress distribution of coal seam floor rocks and quantified the failure depths of floor rocks through theoretical calculations. With the development of geophysical exploration technology, microseismic, acoustic CT detection, and DC resistivity methods have been gradually introduced in coal seam floor damage monitoring [13-20]. 
From the perspective of mechanics, the destruction of coal seam floor rocks always results from the disrupted equilibrium of rock stresses caused by mining actions. During mining, the force of the coal seam floor varies with time, and the floor rocks show corresponding displacements, deformations, and even failures [21, 22]. Therefore, among all the previous theoretical calculations, numerical simulations, and field measurement methods, in situ measurement of the stress or strain of the coal seam floor rocks under active mining is the most direct and effective method for determining the deformation and failure of floor rocks. However, due to the limitations of the specific and nonrepeatable geophysical conditions of in situ field monitoring, only certain factors can be considered, and few in situ monitoring studies including different mining face lengths and water pressure of aquifers have been reported. Therefore, the damage and deformation characteristics of the coal seam floor rocks affected by the water pressure of aquifers in the No. 100502 fully mechanized caving mining face of the Yitang Coal Mine in the Huoxi coal field in the Shanxi Province of China were studied by in situ monitoring. The results can not only provide important guidance for coal mining under water pressure, but also offer a key theoretical reference for failure depth control of floor rocks in mines with similar geophysical conditions.

\section{Field Measurement}

2.1. Field Measurement Area. The area where the field measurements were taken is located at the No. 100502 fully mechanized caving mining face of the Yitang Coal Mine in the Huoxi coal field in the Shanxi Province of China. The mining faces comprise a nearly horizontal coal seam with an average depth of $500 \mathrm{~m}$ and an average thickness of $7.7 \mathrm{~m}$. Due to the influence of the surrounding gobs and fault zones, the length of the mining face is $80 \mathrm{~m}$ at $0 \sim 313 \mathrm{~m}$ along the direction of mining, and the length of residual working face is $180 \mathrm{~m}$ at $314 \sim 1276 \mathrm{~m}$ along the direction of mining. The layout of the No. 100502 working face is shown in Figure 1. The mining roadways are arranged along the floor. The roof of the coal seam is limestone with a thickness of $11 \mathrm{~m}$. The coal seam floor is dominated by mudstone, carbonaceous mudstone, and sandy mudstone. For a better understanding of the lithology of the coal seam floor, an in situ core is drilled from the coal seam to the floor $22.5 \mathrm{~m}$ below. The lithology distribution is determined according to the core samples from in situ drilling [23], and the corresponding mechanical parameters of the strata floor rocks are listed in Table 1.

\subsection{Method of In Situ Field Measurement. For the field} measurement, the in situ strain induction method is used to determine the failure depth of the floor rocks according to the deformation of the floor rocks at different buried depths. In this method, strain sensors are buried in holes at different depths, and the strain evolutions are recorded during the mining process. When the mining face is far away from the strain sensor, and the mining pressure has not reached the sensor, the strain evolution is steady. When the sensor is affected by the mining pressure, the strain evolution changes synchronously with the advancement of mining. When the mining face is worked near the strain sensor, the strains sharply increase due to the intense disturbance of the mining pressure; specifically, if the rocks at the buried position are not yet damaged, the force of the probe is relatively uniform, and the sensor strains change regularly, fluctuating with the deformation of the surrounding rocks during the entire monitoring process. Once the surrounding rocks at the buried positions are disturbed violently, strong plastic displacement and deformation of the drilling hole inevitably occur and damaged plastic coating of the probe or even malfunctions of the probe are resulted; thus, the measured strains are highly discrete or fluctuate randomly [24]. Therefore, the field strain evolutions measured can be used to determine whether the floor rock is damaged or not.

\subsection{Arrangement of Monitoring Holes and Relevant Technical} Parameters. Considering the mining and hydrogeological conditions of the mining face for field measurements, the locations where the initial mine pressure manifested, the locations where the mine pressure were apparent, and the fault zones were selected, and four monitoring boreholes were drilled for field monitoring. The layout of the four monitoring boreholes in the working face can be seen in Figure 1, where two monitoring holes, numbered I and II, were arranged on the $80 \mathrm{~m}$ mining face, and the other two monitoring holes, numbered III and IV, were arranged on the $180 \mathrm{~m}$ mining face. Seventeen hollow body monitoring probe sensors in total were arranged in the four monitoring holes. The four boreholes were arranged with 4, 5, 5, and 3 sensors, respectively, and these sensors were sequentially numbered 1, 2, ., 16, and 17, as seen in Figure 2. Each monitoring hole was arranged at a $30^{\circ}$ angle to the coal seam floor, and these probe sensors were placed in rocks with interval depths to more accurately monitor the stress state of the rocks at different depths. Taking holes I and II on the $80 \mathrm{~m}$ face as examples, the depths of the four monitoring sensors in hole I were $4.93 \mathrm{~m}, 7.93 \mathrm{~m}, 10.93 \mathrm{~m}$, and $14.65 \mathrm{~m}$, and the depths of the monitoring sensors in hole II were $9.50 \mathrm{~m}, 12.50 \mathrm{~m}, 15.50 \mathrm{~m}, 17.50 \mathrm{~m}$, and $19.50 \mathrm{~m}$. The aim of such an arrangement is to accurately determine the failure depth from the data of any two adjacent sensors.

2.4. Field Measurement Equipment. KX-2000 hollow inclusion strain sensors (Figure 3) and KJ 327-F portable digital static-resistance strain indicators (Figure 4) were used in this study for the field measurement. As shown in Figure 3(b), the strain sensor probe consists of 12 resistance strain channels. These strain channels are embedded in an epoxy resin; four strain channels are arranged at intervals of $45^{\circ}$ and form a rectangular resistance array, and three sets of resistance strain arrays are attached to the surface of the hollow inclusion at intervals of $120^{\circ}$. The hollow inclusion sensors can measure strains in the range $\pm 20000 \mu \varepsilon$ with a precision of $\pm 0.1 \%$. Meanwhile, adequate compensation is made to avoid the effect of temperature on the measured strains. 


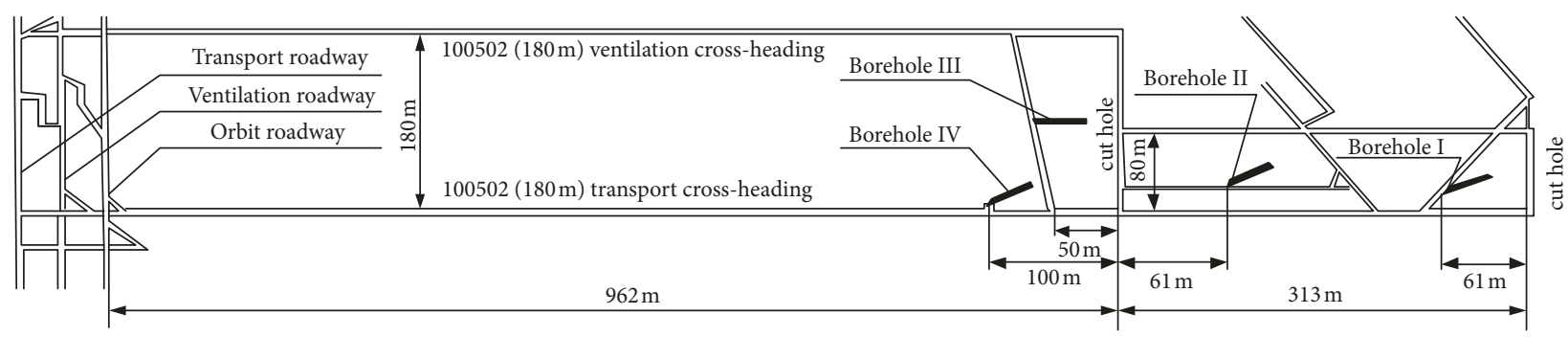

Figure 1: Layout of the No. 100502 mining faces.

TABLE 1: Lithology and mechanical parameters of the floor strata rocks.

\begin{tabular}{|c|c|c|c|c|c|}
\hline Drilling distance from floor & Strata rocks & $\begin{array}{c}\text { Tensile strength } \\
(\mathrm{MPa})\end{array}$ & $\begin{array}{c}\text { Compressive strength } \\
(\mathrm{MPa})\end{array}$ & Poisson ratio & $\begin{array}{c}\text { Elastic modulus } \\
(\mathrm{GPa})\end{array}$ \\
\hline- & Roof & 9.43 & 47.57 & 0.28 & 46.49 \\
\hline - & Coal & 0.36 & 14.60 & 0.25 & 2.50 \\
\hline $2.300-3.570$ & Mudstone & 1.12 & 15.47 & 0.27 & 15.31 \\
\hline $3.570-3.700$ & Allophone mudstone & 1.12 & 15.47 & 0.27 & 15.31 \\
\hline $3.700-4.700$ & Sandy mudstone & 2.61 & 19.71 & 0.26 & 27.00 \\
\hline $4.700-8.700$ & Mudstone & 1.12 & 15.47 & 0.27 & 15.31 \\
\hline $8.700-13.035$ & Allophone mudstone & 1.12 & 15.47 & 0.27 & 15.31 \\
\hline $13.035-13.190$ & Coal & 0.81 & 14.60 & 0.23 & 2.7 \\
\hline $13.190-13.310$ & Carbonaceous mudstone & 2.27 & 23.41 & 0.26 & 10.03 \\
\hline $13.310-13.868$ & Allophone mudstone & 1.12 & 15.47 & 0.27 & 15.31 \\
\hline $13.868-15.874$ & Sandy mudstone & 2.61 & 19.71 & 0.26 & 27.00 \\
\hline $15.874-18.632$ & Mudstone & 2.30 & 15.22 & 0.25 & 8.0 \\
\hline $18.632-20.679$ & Mudstone & 1.12 & 15.47 & 0.27 & 15.31 \\
\hline $20.679-22.500$ & Sandstone & 10.95 & 55.26 & 0.21 & 22.67 \\
\hline
\end{tabular}

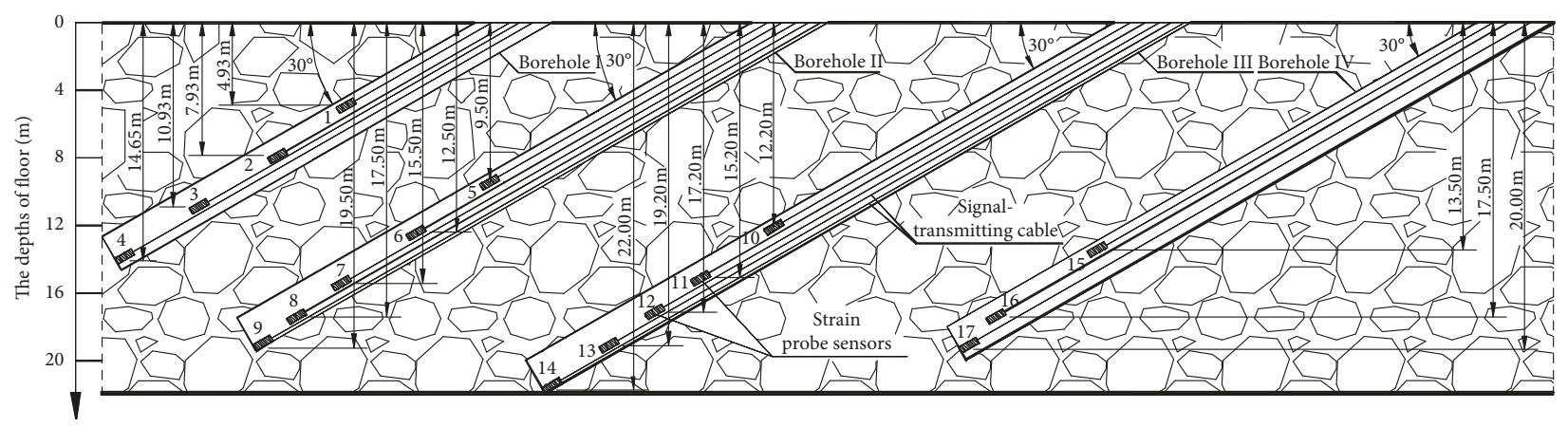

Figure 2: Layout parameters of the sensors.

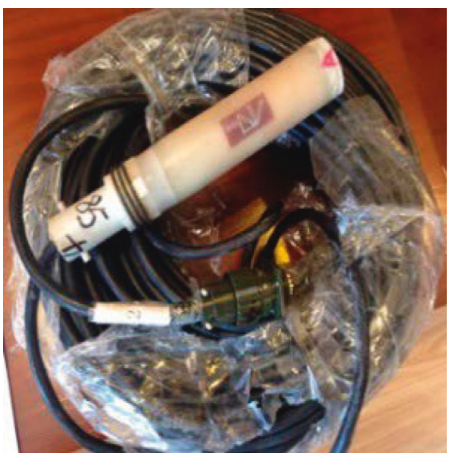

(a)

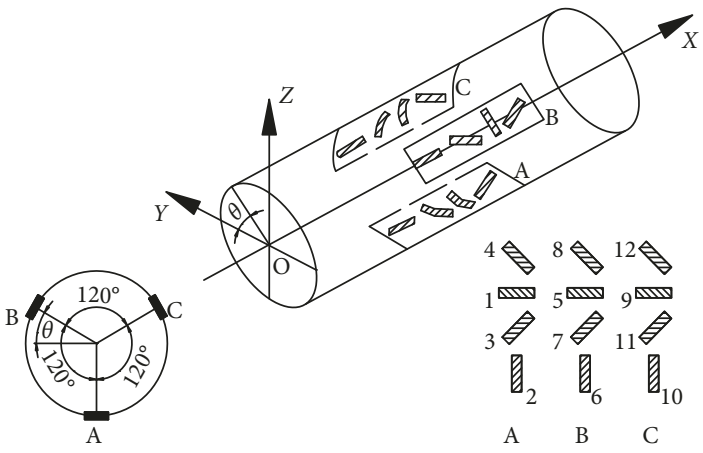

(b)

Figure 3: KX-2000 hollow inclusion strain sensors. (a) Strain sensor probe. (b) Internal structure of the strain sensor probe. 


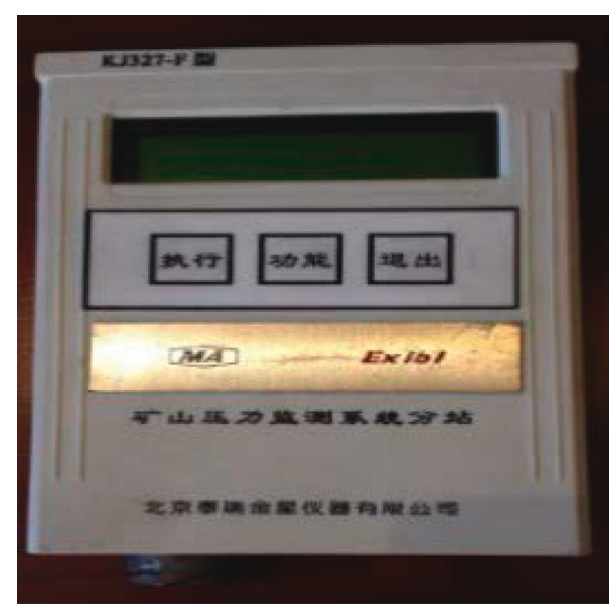

Figure 4: KJ 327-F portable digital static-resistance strain indicator.

2.5. Data Monitoring. After the probes were installed at the predetermined positions in each monitoring hole, the holes were filled with cement grout that was allowed to harden for 28 days before the initial strains of the probe sensors were measured. After actual mining officially started in the working face, the advancement distances of the mining face and the corresponding strains of each probe sensor were recorded every day. During the field measurements, to ensure that the real-time strains were unaffected by unfavorable factors such as coal mining and human activities, each strain data from the probe sensor was measured by the maintenance crew every day at intervals of 30 minutes. The entire field measurements lasted for eight months.

\section{Field Measurement Results}

The strain increment is defined as the difference between the real-time strain and the initial strain of each sensor probe, and the evolution of the strain increment is used to characterize the stress and deformation of the coal seam floor rocks before and after mining. Figures 5 and 6 show the evolutions of the strain increments of the seventeen sensor probes in the four holes in the $100502(80 \mathrm{~m})$ and 100501 $(180 \mathrm{~m})$ faces during the mining process. The abscissa is the horizontal distance from the mining face to the monitoring sensor probe; a positive value indicates that the mining face has not yet passed the monitoring sensor probe, while a negative value means that the mining face has passed the monitoring sensor probe, and the zero point is the position of the sensor probe. The ordinate is the strain increment, and a positive value means that the sensor probe is in a tensile state, while a negative value means that the sensor probe is in a compressive state.

Figures 5 and 6 show that the strain increment of each probe sensor (\#1 17) is almost unchanged in the initial stage after mining begins, and fluctuates gradually due to the mining pressure as the mining face advances towards the sensor probe. For example, when the mining face is horizontally $42.5 \sim 36.7 \mathrm{~m}$ away from sensor probe \# 1 , the strain increment remains generally unchanged, as shown in
Figure 5(a). This consistency occurs because the monitoring sensor probe is far away from the mining face, and such distances exceed the influence range of the advanced support pressure. With the continuous advancement of the mining face, the monitoring sensor probe is affected by the advanced support pressure, and the strain increment changes gradually when the mining face is horizontally $36.7 \sim 28.9 \mathrm{~m}$ away from the sensor probe. In the subsequent monitoring process, the coal seam floor rocks fracture due to the mining pressure and advanced support pressure, and the corresponding strain increment shows violent fluctuations.

In addition, there are some abnormal variations in the strain increment curves of certain probe sensors, for example, the strain monitoring channels 5, 7, and 9 of sensor probe $\# 8$ undergo out of range strain responses during the entire monitoring process. These responses may result from the strain-monitoring probe coming into direct contact with the surrounding rocks and generating concentrated stress as the mining face advanced, so the strain increment data of the three channels monitored are out of order. Similarly, all the strain-monitoring channels in sensor probe \#12 are disordered with strain increments of approximately 1000 2000 $\mu \varepsilon$ throughout the monitoring process. These results may be due to the effect of significant nonuniform deformation of the surrounding rocks around the measuring points. All the abnormal data need to be removed. However, considering the structure of the strain probe sensor, each sensor comprises 12 channels; even though some data are removed, the remaining channels and other strain sensor probes can still accurately monitor the overall strain increments in the borehole. Therefore, despite the appearance of abnormal strain increments, the overall field measurement results are scientific and reliable.

\section{Deformation and Failure Law of Floor Rocks}

4.1. Failure Types of the Strain Increments of the Floor Rocks. As shown in Figures 5 and 6, the strain increment curves of several sensor probes changed coordinately as the mining face advanced, for example, all the strain increment curves of sensor probes \#4, 7, 8, 9, 17, 13, and 14 showed coordinated changes throughout the entire monitoring time. Although there were some sudden strain changes at certain positions, the strain increment curves gradually recovered in subsequent monitoring, which suggests that the rocks in these locations were elastically deformed, and no plastic damage was caused. In contrast, the strain increment curves of the other sensor probes abruptly changed at certain locations in the measurement process without subsequent recovery, which indicates that the coal seam floor rocks at these locations were destroyed. The strain increment curves with abrupt changes could be divided into two types: tensilecompressive strain mutations and abnormal mutations.

(a) Tensile-compressive strain mutations

As shown in Figures 5 and 6, the strain increment curves of sensor probes $\# 1,5,6,10,11,15$, and 16 showed coordinated change at the initial stage of monitoring; however, as the mining face advanced continuously, at positions 


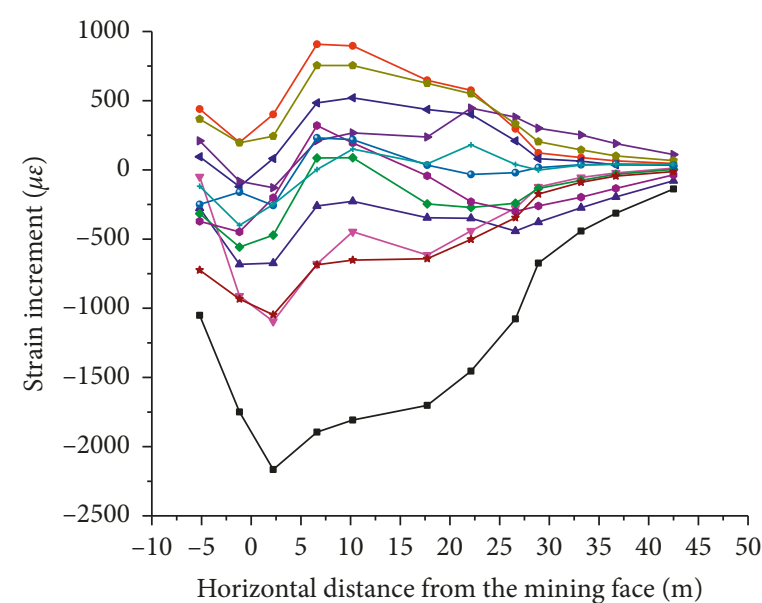

$\begin{array}{llll}\rightarrow 1 & \rightarrow 4 & \rightarrow-7 & \rightarrow 10 \\ \rightarrow 2 & \rightarrow 5 & \rightarrow-8 & \rightarrow 11 \\ -3 & \leftarrow 6 & \rightarrow 9 & \rightarrow 12\end{array}$

(a)

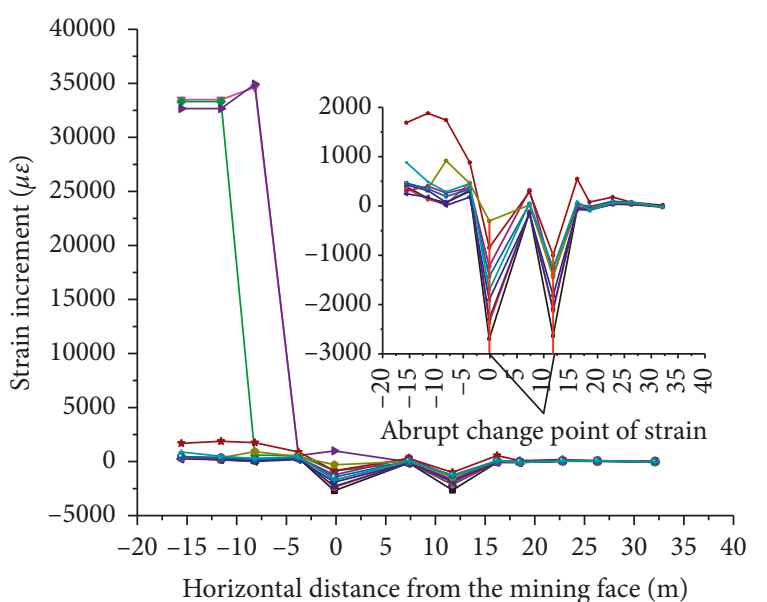

$\begin{array}{llll}\rightarrow 1 & \rightarrow & \rightarrow-7 & \rightarrow-10 \\ \rightarrow 2 & \rightarrow 5 & \rightarrow-8 & \rightarrow-11 \\ -3 & \leftarrow 6 & \rightarrow-9 & \rightarrow 12\end{array}$

(c)

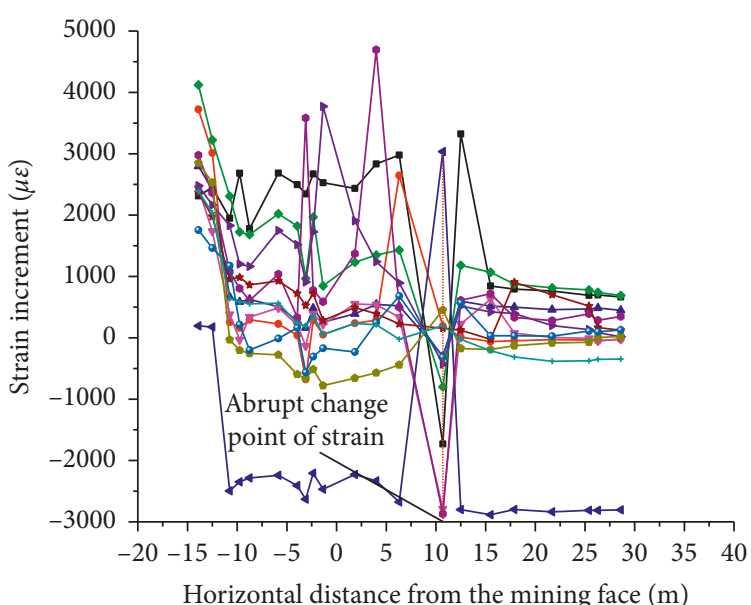

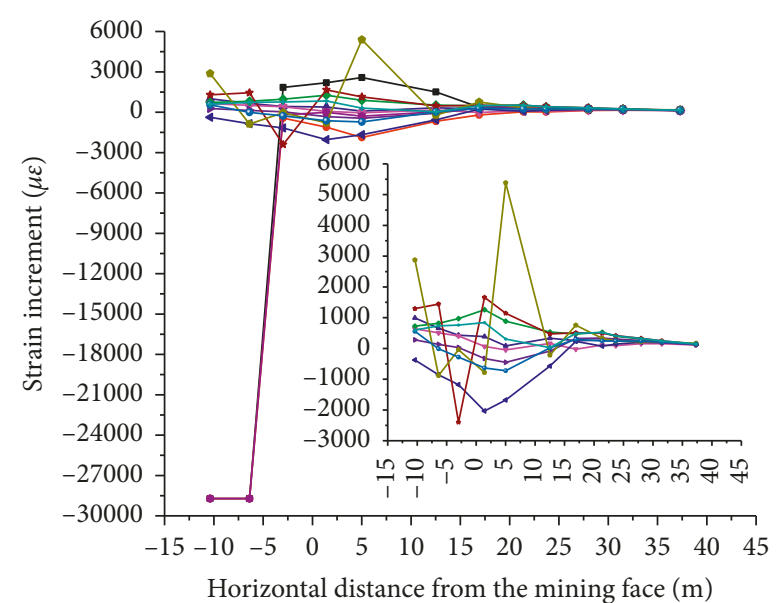

$\rightarrow 1 \rightarrow 4 \rightarrow 7 \rightarrow-70$

$\because 2 \quad \rightarrow 5 \quad \rightarrow 8 \quad \rightarrow 11$

$\leftarrow 3 \rightarrow 6 \rightarrow 9 \rightarrow 12$

(b)

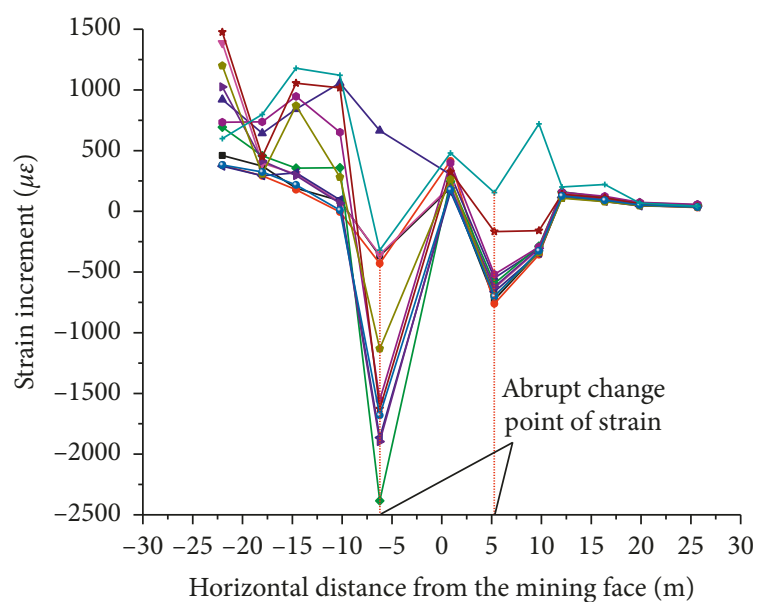

$\begin{array}{llll}\rightarrow 1 & \rightarrow & \rightarrow-7 & \rightarrow 10 \\ \rightarrow 2 & \rightarrow 5 & \rightarrow 8 & \rightarrow 11 \\ -3 & \rightarrow 6 & \rightarrow-9 & \longrightarrow 12\end{array}$

(d)

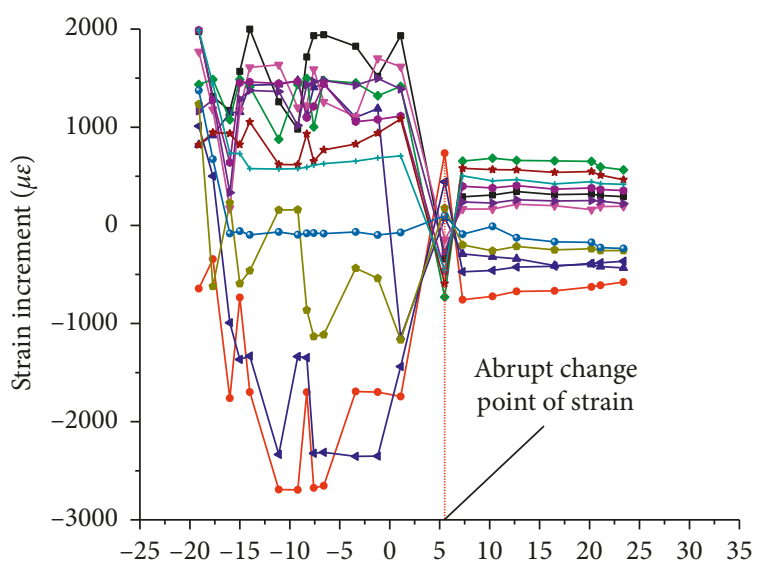

Horizontal distance from the mining face $(\mathrm{m})$

$\begin{array}{llll}\rightarrow 1 & \rightarrow 4 & \rightarrow 7 & \rightarrow 10 \\ -2 & \rightarrow 5 & \rightarrow 8 & \rightarrow 11 \\ -3 & \rightarrow 6 & \rightarrow-9 & \rightarrow 12\end{array}$

(f)

(e)

Figure 5: Continued. 


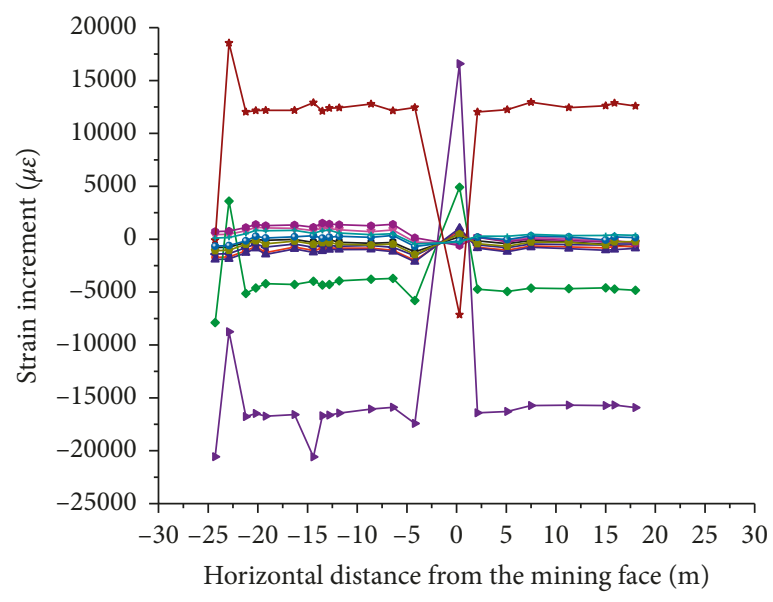

$\begin{array}{llll}\rightarrow 1 & \rightarrow 4 & \rightarrow-7 & \rightarrow 10 \\ \rightarrow 2 & \rightarrow 5 & \rightarrow-8 & \rightarrow 11 \\ -3 & \rightarrow 6 & \rightarrow-9 & \rightarrow 12\end{array}$

(g)

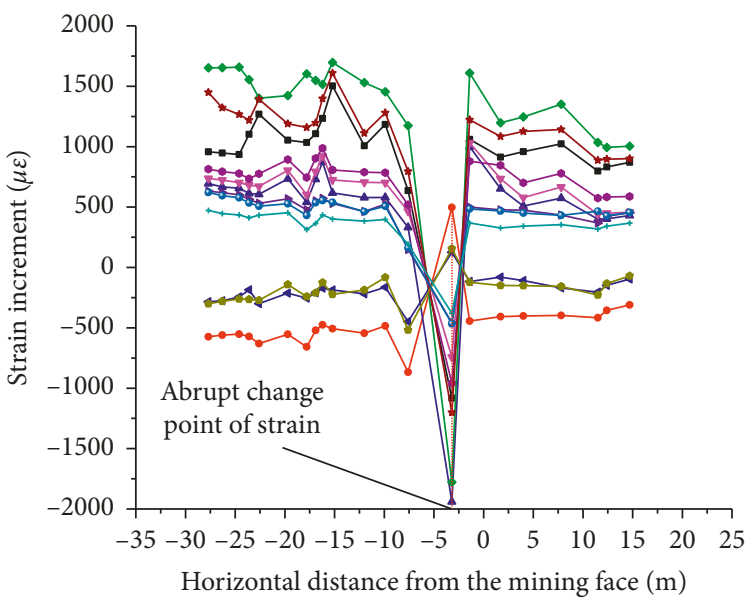

$\begin{array}{llll}\rightarrow 1 & \rightarrow & \rightarrow-7 & \rightarrow 10 \\ \rightarrow 2 & \rightarrow 5 & \rightarrow-8 & \rightarrow 11 \\ -3 & \leftarrow 6 & \rightarrow-9 & \rightarrow 12\end{array}$

(i)

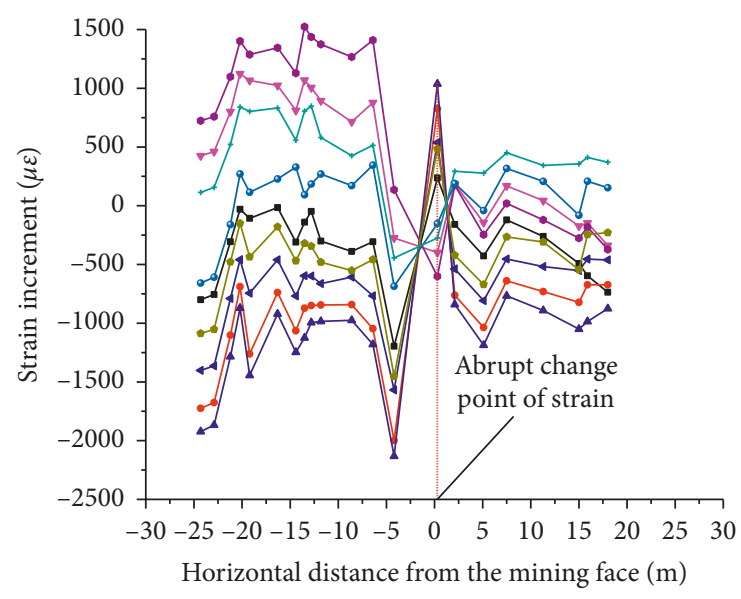

$\begin{array}{lll}\rightarrow 1 & \rightarrow 4 & \rightarrow 10 \\ \rightarrow 2 & \because 6 & \rightarrow 11 \\ -3 & \rightarrow-8 & \rightarrow 12\end{array}$

(h)

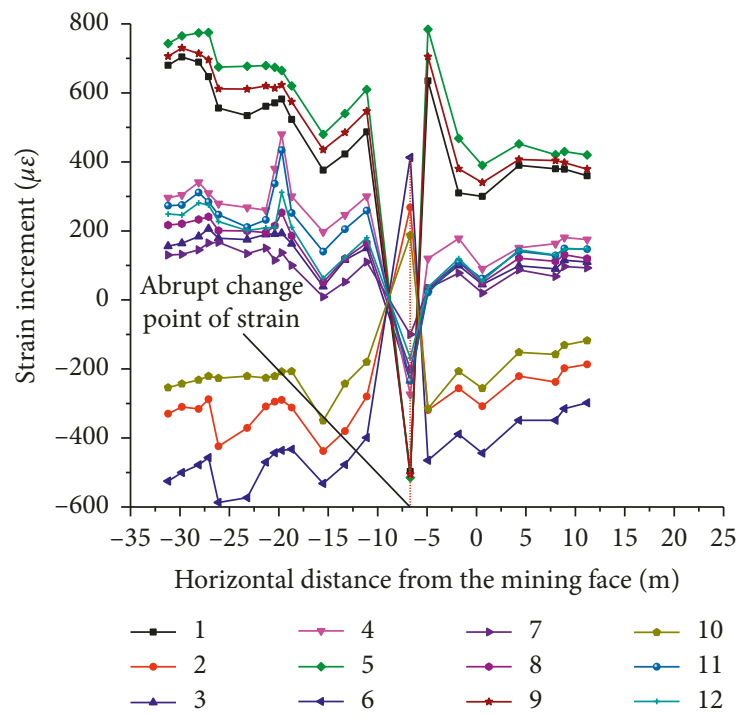

(j)

FIgURE 5: Strain increment curves of each sensor in boreholes I and II in the 100502 (80 m) mining face. (a) Sensor \#1. (b) Sensor \#2. (c) Sensor \#3. (d) Sensor \#4. (e) Sensor \#5. (f) Sensor \#6. (g) Sensor \#7. (h) Sensor \#7 after abnormal data are removed. (i) Sensor \#8. (j) Sensor \#9.

where the mining face was horizontally $28.9 \mathrm{~m}, 12.5 \mathrm{~m}, 5.5 \mathrm{~m}$, $5.07 \mathrm{~m},-3.43 \mathrm{~m}, 14.72 \mathrm{~m}$, and $11.39 \mathrm{~m}$ away from the above buried sensor probes, respectively, the strain increment curves showed sudden changes, which suggests that the surrounding rocks around these buried sensor probes had been damaged. In addition, the strain increments generally converted from compressive strain to tensile strain, and mutations resulted at these locations. That may be attributed to the plastic destruction of the surrounding rocks and sudden stress released at these locations. Taking probes \#5 and 6 as examples, when the floor rocks were not damaged, their strain increments ranged from $+1000 \sim-1000 \mu \varepsilon$, and the rocks at the buried locations were elastically deformed. When the sensor probes were affected by the advanced abutment pressure from mining actions, the floor rocks were gradually damaged, and the strain increments fluctuated violently, ranging from
$+5000 \sim-3000 \mu \varepsilon$ and $+2000 \sim-3000 \mu \varepsilon$, respectively. There were obvious tensile-compressive strain mutations in the strain increment curves at positions where the mining face was horizontally $10.7 \mathrm{~m}$ and $5.5 \mathrm{~m}$ away from the sensor probes, respectively. In addition, the later monitoring data show that there was no recovery in the strain increment curves, and the subsequent monitoring data of each channel was highly discrete. Therefore, the floor rocks at the buried locations of the two sensor probes had undergone plastic destruction.

(b) Abnormal mutations

The strain increment curves of sensor probes \#2 and 3 showed abnormal mutations. The strain increment curves of probes $\# 2$ and 3 varied slightly at the initial stage of monitoring; however, the strain increment curves fluctuated 

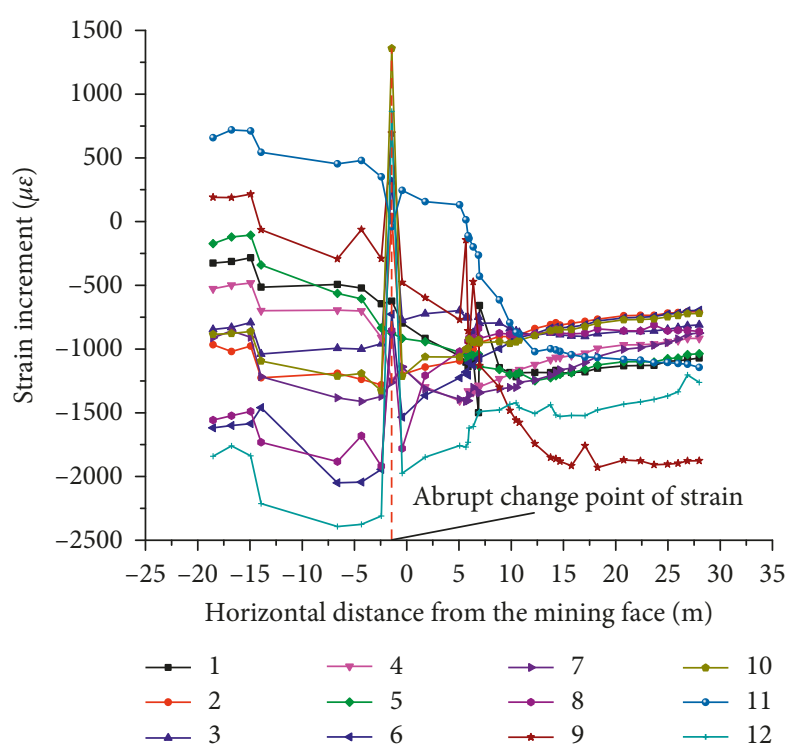

(a)
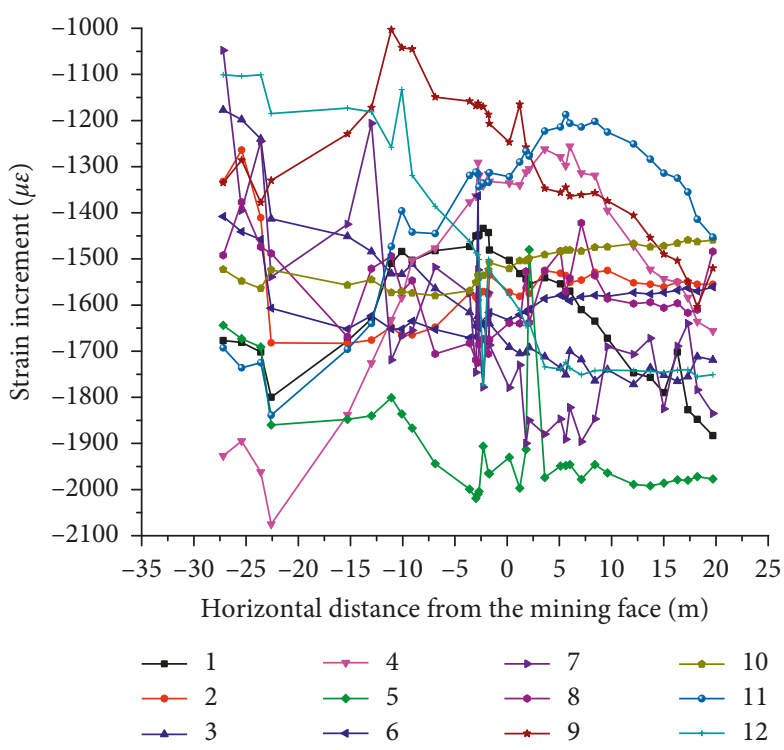

(c)

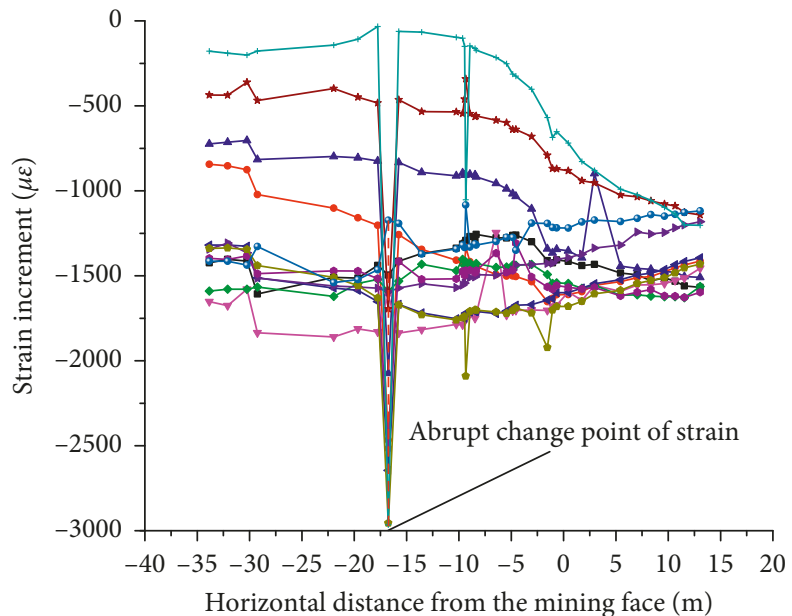

$\begin{array}{llll}\rightarrow 1 & \rightarrow & \rightarrow-7 & \rightarrow 10 \\ \rightarrow 2 & \rightarrow 5 & \rightarrow-8 & \rightarrow 11 \\ -3 & \rightarrow 6 & \rightarrow-9 & \rightarrow 12\end{array}$

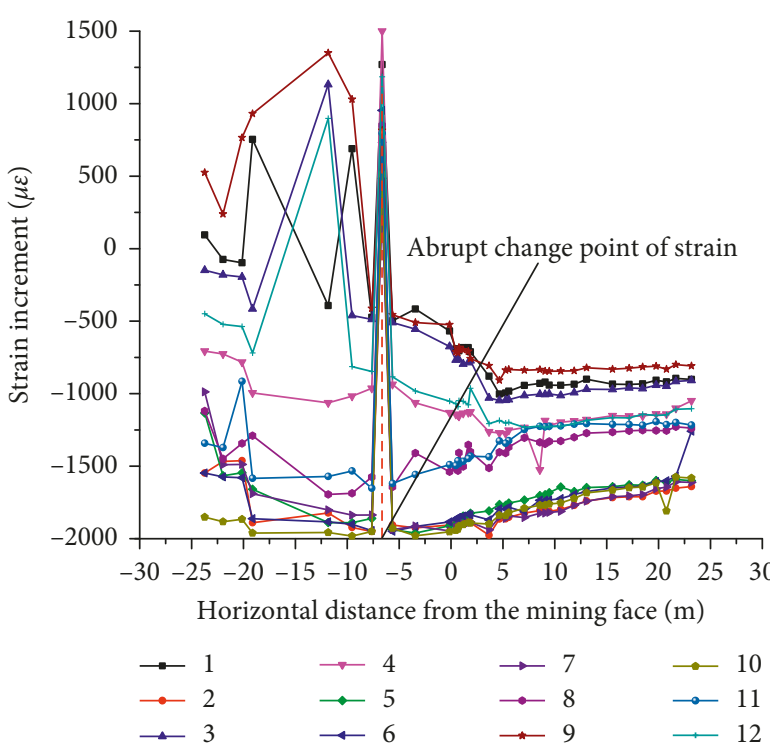

(b)

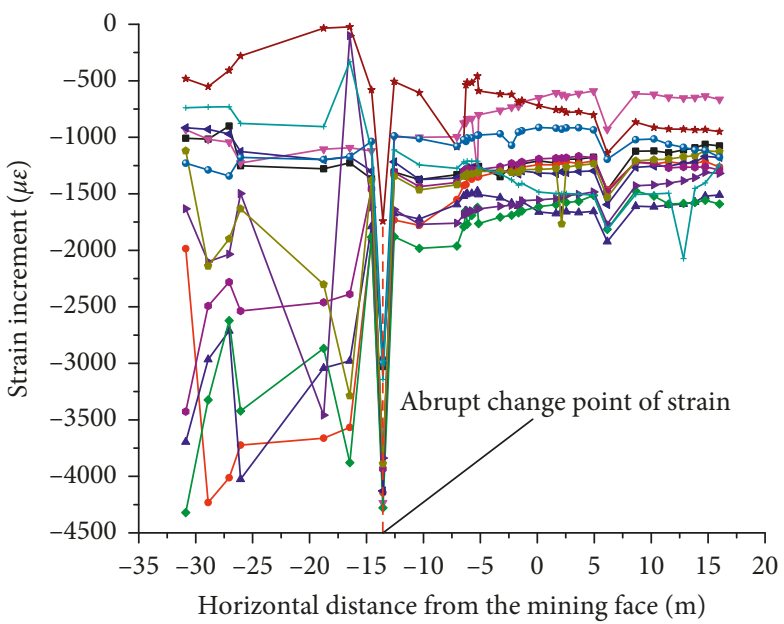

$\begin{array}{llll}\rightarrow 1 & \rightarrow 4 & \rightarrow-7 & \rightarrow-10 \\ -2 & \rightarrow 5 & \rightarrow 8 & \rightarrow 11 \\ -3 & -6 & \rightarrow-9 & \rightarrow 12\end{array}$

(d)

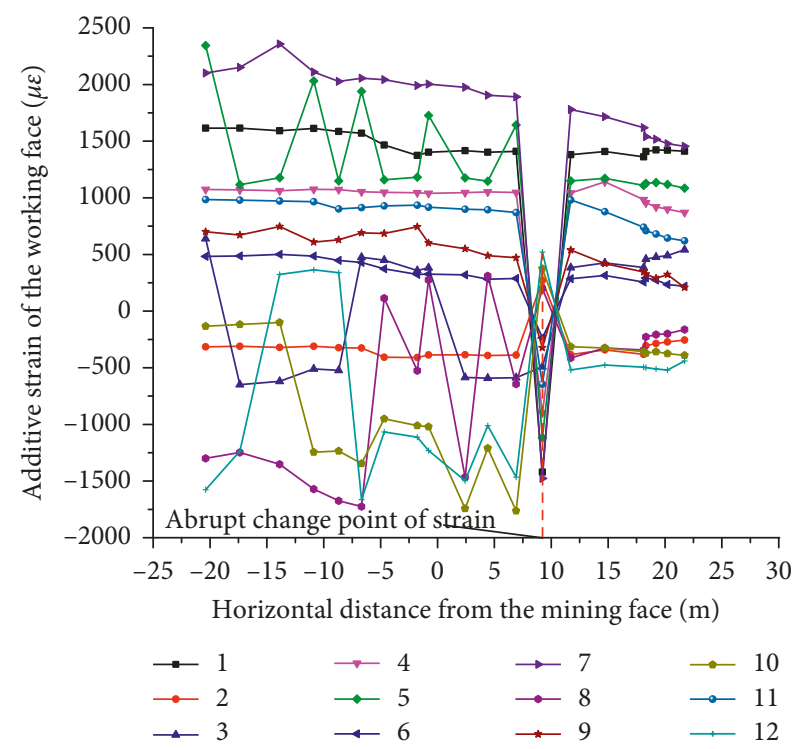

(f)

FIgURE 6: Continued. 


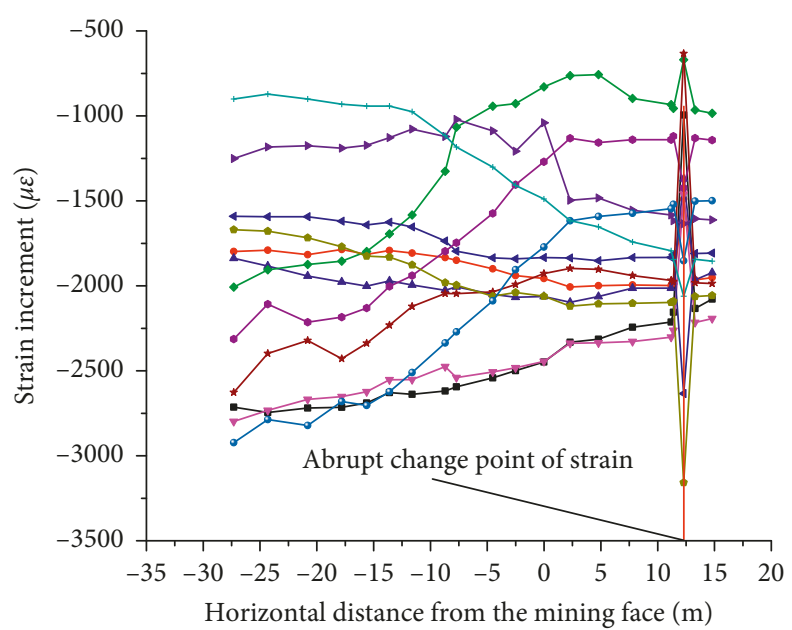

$\begin{array}{llll}\rightarrow 1 & \rightarrow 4 & \rightarrow-7 & \rightarrow-10 \\ \rightarrow 2 & \rightarrow 5 & \rightarrow-8 & \rightarrow-11 \\ -3 & \rightarrow 6 & \rightarrow-9 & \rightarrow-12\end{array}$

(g)

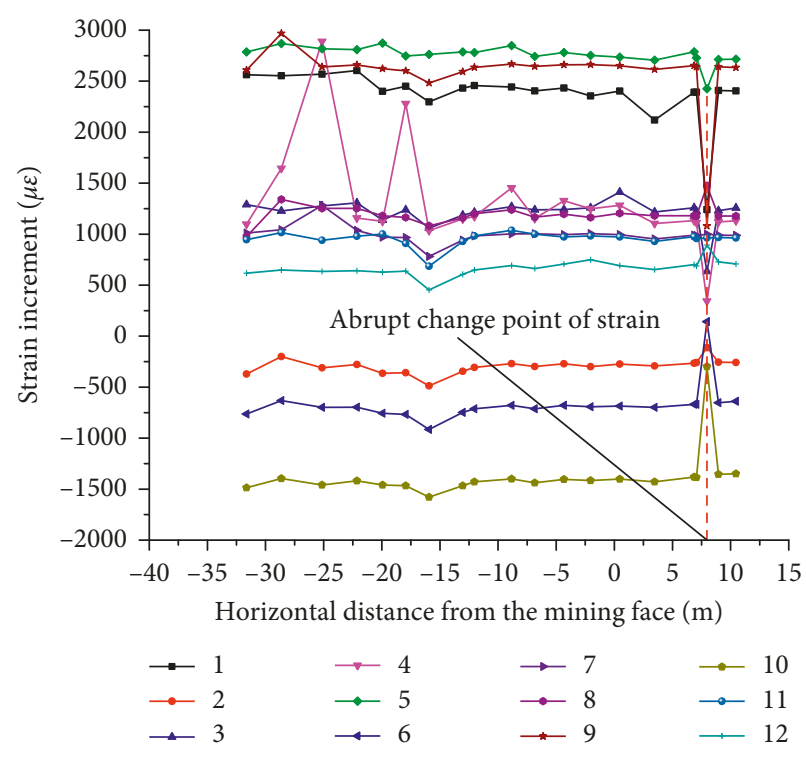

(h)

FIGURE 6: Strain increment curves of each sensor in boreholes III and IV in the 100502-180 mining face. (a) Sensor \#10. (b) Sensor \#11. (c) Sensor \#12. (d) Sensor \#13. (e) Sensor \#14. (f) Sensor \#15. (g) Sensor \#16. (h) Sensor \#17.

drastically, ranging from $+6000 \sim-3000 \mu \varepsilon$, and when the mining face was horizontally $2.98 \mathrm{~m}$ and $-3.77 \mathrm{~m}$ away from the sensor probes, respectively, the strain increments were beyond the measuring range. In addition, no recovery in the strain increment curves was seen in the subsequent monitoring. These results all indicate that the floor rocks around the sensor probes were fractured and that the strain gauge inside might have touched the sharp rocks; thus, the strain increments changed abruptly, showing abnormal mutation, without recovery.

4.2. Failure Depth of the Coal Seam Floor. From the strain increment curves of the seventeen sensor probes in the four monitoring boreholes, the floor rocks damage characteristics are listed below (Table 2).

In the mining face with a length of $80 \mathrm{~m}$, the failure depth of the coal seam floor rocks affected by mining actions is $12.50 \sim 14.65 \mathrm{~m}$, and when the mining face length increases to $180 \mathrm{~m}$, the failure depth is $17.50 \sim 19.20 \mathrm{~m}$. The larger the mining face length is, the greater the failure depth of the floor rocks affected by the mining actions is. This result may be due to the increase in the length of the mining face and the corresponding increase in mining pressure, thereby increasing the failure depth of the floor rocks.

\subsection{Advanced and Lagged Response Properties of the Strain} Increment. From the overall monitoring curves of each probe, the strain increment curves showed obvious advanced and lagged response properties. Over the entire monitoring period, the strain increment curves sensed and responded even before the mining face advanced to the buried locations of the sensor probes, presenting advanced sensor properties. In addition, as the mining face passed the monitoring holes, the strain increment curves did not reinstate immediately but began to reinstate gradually after the mining face was a few meters past the monitoring holes, showing lagged response properties. For example, the strain increment curves of probe \#4 in Figure 5(d) show obvious advanced strain responses before the mining face reached the buried locations of the sensor probe. The strain increments increased slowly when the mining face was horizontally $12.06 \mathrm{~m}$ away from the sensor probe, and the strain increments dropped sharply when the mining face was horizontally $5.28 \mathrm{~m}$ away from the sensor probe; the strain increments generally exhibited advanced response characteristics. In addition, when the mining face passed over the sensor probe, the strain increments did not recover immediately but reinstated to initial strains after the mining face had horizontally passed the sensor probe by $18.02 \mathrm{~m}$; thus, lagged response characteristics were presented. The advanced response distances and lagged response distances of the strain increment of each probe were counted and shown in Figures 7 and 8.

Figure 7 shows that the advanced response distances decreased approximately following a negative exponential function as the burial depth of each sensor probe increased. This decrease occurs because during the transmission of the advanced support pressure to the floor rocks, the stress decreased gradually with increasing transmission distance, and the further the transmission distance, the more stress loss. For the probes at the same burial depths, the longer the mining face was, the greater the advanced response distance. This correlation occurs because mine pressure significantly increased as the length of the mining face increased; therefore, a more intense strain response and a greater advanced response distance resulted.

Figure 8 shows that the lagged response distance first increased and then decreased as the burial depth of the probes increased. In addition, the lagged response distance 
TABLE 2: Failure and damage characteristics of the floor rocks at the buried locations of each probe sensor.

\begin{tabular}{|c|c|c|c|c|c|}
\hline Mining face & Probe sensor & Buried depth (m) & Failure or not & Mutation type & Failure depth $(\mathrm{m})$ \\
\hline \multirow{9}{*}{$100502-80$} & 1 & 4.93 & $\mathrm{Y}$ & Pull-pressure strain mutation & \multirow{9}{*}{$12.5-14.65$} \\
\hline & 2 & 7.93 & $\mathrm{Y}$ & Abnormal mutation & \\
\hline & 5 & 9.5 & $\mathrm{Y}$ & Pull-pressure strain mutation & \\
\hline & 3 & 10.93 & $\mathrm{Y}$ & Abnormal mutation & \\
\hline & 6 & 12.5 & $\mathrm{Y}$ & Pull-pressure strain mutation & \\
\hline & 4 & 14.65 & $\mathrm{~N}$ & - & \\
\hline & 7 & 15.5 & $\mathrm{~N}$ & - & \\
\hline & 8 & 17.5 & $\mathrm{~N}$ & - & \\
\hline & 9 & 19.5 & $\mathrm{~N}$ & - & \\
\hline \multirow{8}{*}{$100502-180$} & 10 & 12.2 & $\mathrm{Y}$ & Pull-pressure strain mutation & \multirow{8}{*}{$17.5-19.2$} \\
\hline & 15 & 13.5 & $\mathrm{Y}$ & Pull-pressure strain mutation & \\
\hline & 11 & 15.2 & $\mathrm{Y}$ & Pull-pressure strain mutation & \\
\hline & 12 & 17.2 & Probe damaged & - & \\
\hline & 16 & 17.5 & $\mathrm{Y}$ & \multirow{4}{*}{$\begin{array}{l}\text { Pull-pressure strain mutation } \\
\qquad \begin{array}{c}- \\
-\end{array}\end{array}$} & \\
\hline & 13 & 19.2 & $\mathrm{~N}$ & & \\
\hline & 17 & 20 & $\mathrm{~N}$ & & \\
\hline & 14 & 22 & $\mathrm{~N}$ & & \\
\hline
\end{tabular}

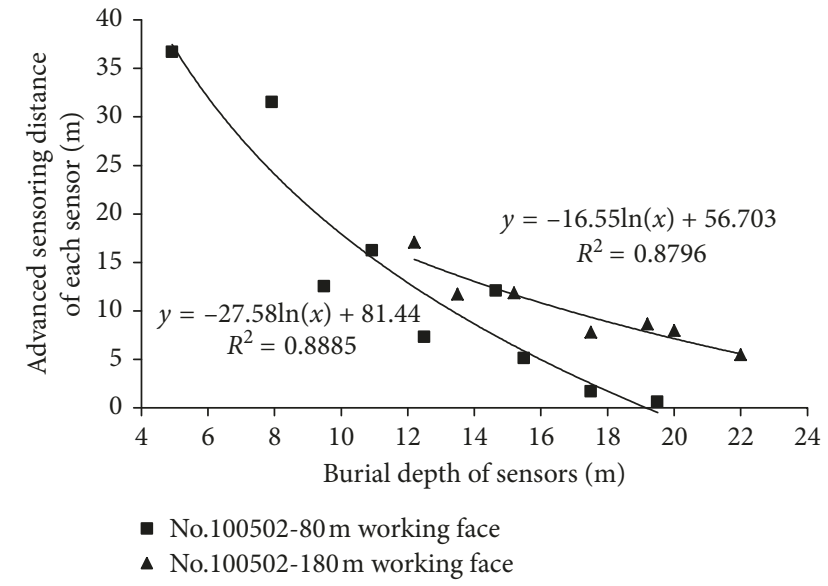

FIgURE 7: Relationship between the buried depths of the sensors and their advanced response distances.

dropped more rapidly at the declining stage for the mining face with a greater length. The lagged response property occurs because during the advancement of mining face, the pressure of the floor rocks at the locations of the buried probe was not thoroughly relieved until the mining face was a few meters past the monitoring hole.

From the perspective of force, the advanced and lagged sensing properties of the strain increments of the floor rocks were caused by disruption to the original balance of the ambient stresses. To better explore the mining-induced advanced and lagged characteristics of the strain increment responses of the floor rocks, the force diagram of the rocks in front of the mining face is illustrated in Figure 9. During the advancement of the mining face, the rocks affected by the advanced support force in front of the mining face can be divided into four pressure zones according to their force characteristics: an active pressure zone, a transition zone, a passive pressure zone, and a floor heaving zone. When the mining face had not yet advanced to the

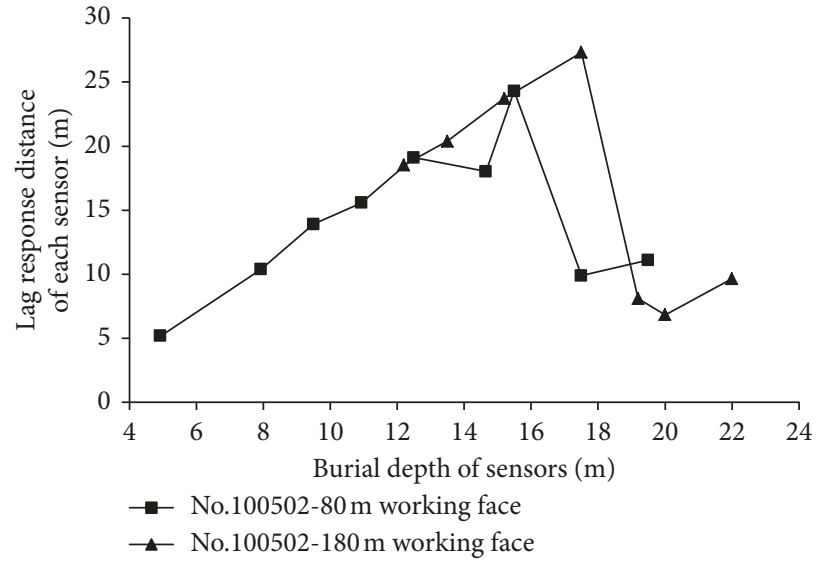

FIGURE 8: Relationship between the buried depths of the sensors and their lagged response distances.

buried locations of the sensor probes, the sensor probes had sensed and changed already owing to the advanced support force; thus, advanced sensing occurred. Meanwhile, when the mining face passed the monitoring hole, the sensor probe was still in the transition zone, and thus still was influenced by the advanced support force; therefore, a lagged response was detected for the strain increment.

\section{Conclusions}

The $100502(80 \mathrm{~m}, 180 \mathrm{~m})$ mining faces in the Huoxi Coal Field in North China were chosen for in situ monitoring, and the mining-induced characteristics of the floor rocks were studied. The main results are as follows:

(1) The abrupt changes in the strain increment curves of each sensor could be divided into two types regarding the failure of the damaged floor rocks: tensile-compressive strain mutations and abnormal mutations. 


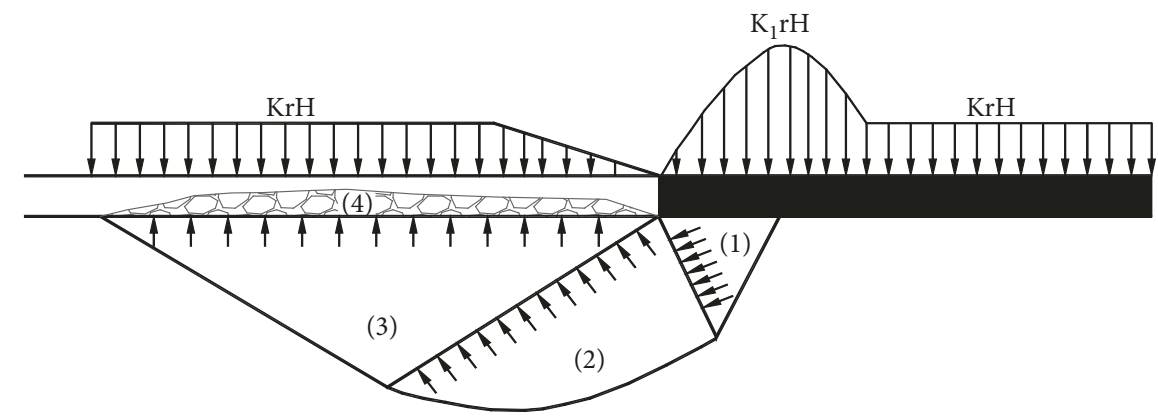

Figure 9: Illustration of different force structures in the mining floor. (1) Subjective pressure zone. (2) Transition zone. (3) Passive pressure zone. (4) Floor heaving zone.

(2) The failure depths of the floor rocks in the 100502 $(80 \mathrm{~m})$ and $100502(180 \mathrm{~m})$ mining faces were $12.50 \sim 14.65 \mathrm{~m}$ and $17.50 \sim 19.20 \mathrm{~m}$, respectively. The longer the mining face was, the greater the failure depth and the more severe the deformation and damage of the floor rocks were.

(3) The strain increments of each sensor probe at different depths showed obvious advanced and lagged response properties. As the depth increased, the advanced response distance decreased in a negative exponential trend, while the lagged response distance generally first increased and then decreased.

\section{Data Availability}

The data used to support the findings of this study are included within the article.

\section{Conflicts of Interest}

The authors declare that they have no conflicts of interest.

\section{Acknowledgments}

The support for this work was provided by the National Natural Science Foundation of China (No. 51704204), which is greatly appreciated by the authors.

\section{References}

[1] C. P. Please, D. P. Mason, A. J. Hutchinson et al., "Fracturing of an Euler-Bernoulli beam in coal mine pillar extraction," International Journal of Rock Mechanics and Mining Science, vol. 64, pp. 132-138, 2013.

[2] T. B. Zhao, W. Y. Guo, Y. L. Tan, Y. C. Yin, L. S. Cai, and J. F. Pan, "Case studies of rock bursts under complicated geological conditions during multi-seam mining at a depth of 800 m," Rock Mechanics and Rock Engineering, vol. 51, no. 5, pp. 1539-1564, 2018.

[3] W. Y. Guo, T. B. Zhao, Y. L. Tan, F. H. Yu, S. C. Hu, and F. Q. Yang, "Progressive mitigation method of rock bursts under complicated geological conditions," International Journal of Rock Mechanics and Mining Sciences, vol. 96, pp. 11-22, 2017.
[4] D. J. Xu, S. P. Peng, S. Y. Xiang et al., “"'The effects of caving of a coal mine's immediate roof on floor strata failure and water inrush," Mine Water and the Environment, vol. 35, no. 3, pp. 337-349, 2016.

[5] J. C. Zhang, Y. Z. Zhang, and T. Q. Liu, Rock Seepage and Coal Floor Water Inrush, Geological Press, Beijing, China, 1997.

[6] X. G. Gu, J. C. Wang, and Y. D. Liu, "Water resistant features of high-risk outburst coal seams and standard discriminant model of mining under water-pressure," Mining Science and Technology, vol. 20, no. 6, pp. 797-802, 2010.

[7] C. F. Santos and Z. T. Bieniawski, "Floor design in underground coal mines," Rock Mechanics and Rock Engineering, vol. 22, no. 4, pp. 249-271, 1989.

[8] Z. Y. Wang, H. Q. Liu, P. Y. Wang et al., "Theory and practice of coal mining disciple on confined water," Journal of China Coal Society, vol. 19, no. 1, pp. 40-48, 1994.

[9] X. G. Li and Y. F. Gao, "Analysis of failure and damage of rock floor in stope," Chinese Journal of Rock Mechanics and Engineering, vol. 22, no. 1, pp. 35-39, 2003.

[10] H. Y. Yin, L. Lefticariu, J. C. Wei et al., "In situ dynamic monitoring of stress revolution with time and space under coal seam floor during longwall mining," Environmental Earth Science, vol. 75, no. 18, p. 1249, 2016.

[11] S. Y. Zhu, Z. Q. Jiang, K. J. Zhou et al., "The characteristics of deformation and failure of coal seam floor due to mining in Xinmi coal field in China," Bulletin of Engineering Geology and the Environment, vol. 73, no. 4, pp. 1151-1163, 2014.

[12] L. G. Wang, Y. Wu, and J. Sun, "Three-dimensional numerical simulation on deformation and failure of deep stope floor," Procedia Earth and Planetary Science, vol. 1, no. 1, pp. 577584, 2009.

[13] L. C. Wang, "Mine geological radar method and application," Journal of China Coal Society, vol. 25, no. 1, pp. 5-9, 2000.

[14] J. L. Chen, S. J. Yu, Y. Song et al., "Experimental research on sound wave CT detection of coal floor destruction depth," Journal of China Coal Society, vol. 24, no. 6, pp. 576-580, 1999.

[15] X. R. Meng, C. H. Xu, Z. N. Gao et al., "Stress distribution and damage mechanism of mining floor," Journal of China Coal Society, vol. 35, no. 11, pp. 1832-1836, 2010.

[16] W. F. Brace and A. S. Orange, "Electrical resistivity changes in saturated rocks during fracture and frictional sliding," Journal of Geophysical Research, vol. 73, no. 4, pp. 1433-1445, 1968.

[17] S. Li, C. J. Fan, M. K. Luo et al., "Structure and deformation measurements of shallow overburden during top coal caving longwall mining," International Journal of Mining Science and Technology, vol. 27, pp. 1081-1085, 2017. 
[18] J. P. Xu, W. H. Sui, H. Gui et al., "Utilizing angular displacement to monitor failure of coal seam floor," Procedia Earth and Planetary Science, vol. 1, no. 1, pp. 943-948, 2009.

[19] Z. M. Xu, Y. J. Sun, S. Y. Gong et al., "Monitoring and numerical simulation of formation of water inrush pathway caused by coal mining above confined water with high pressure," Chinese Journal of Rock Mechanics and Engineering, vol. 1, no. 8, pp. 1698-1704, 2012.

[20] Q. Wu, B. Zhu, and S. Q. Liu, "Flow-solid coupling simulation method analysis and time identification of lagging waterinrush near mine fault belt," Chinese Journal of Rock Mechanics and Engineering, vol. 30, no. 1, pp. 93-104, 2011.

[21] A. M. Suchowerska, R. S. Merifield, and J. P. Carter, "Vertical stress changes in multi-seam mining under supercritical longwall panels," International Journal of Rock Mechanics and Mining Science, vol. 61, pp. 306-320, 2013.

[22] A. K. Singh, R. Singh, J. Maiti et al., "Assessment of mining induced stress development over coal pillars during depillaring," International Journal of Rock Mechanics and Mining Science, vol. 48, no. 5, pp. 805-818, 2011.

[23] W.-Y. Guo, Y.-L. Tan, Y. Feng-hai et al., "Mechanical behavior of rock-coal-rock specimens with different coal thicknesses," Geomechanics and Engineering, vol. 15, no. 4, pp. 1017-1027, 2018.

[24] R. Zhang, Z. Jiang, X. Li, H. Chao, and Q. Sun, "Study on the failure depth of thick seam floor in deep mining," Journal of China Coal Society, vol. 38, no. 1, pp. 67-72, 2013. 


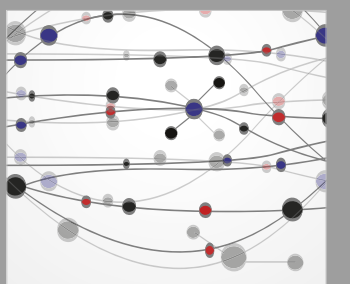

The Scientific World Journal
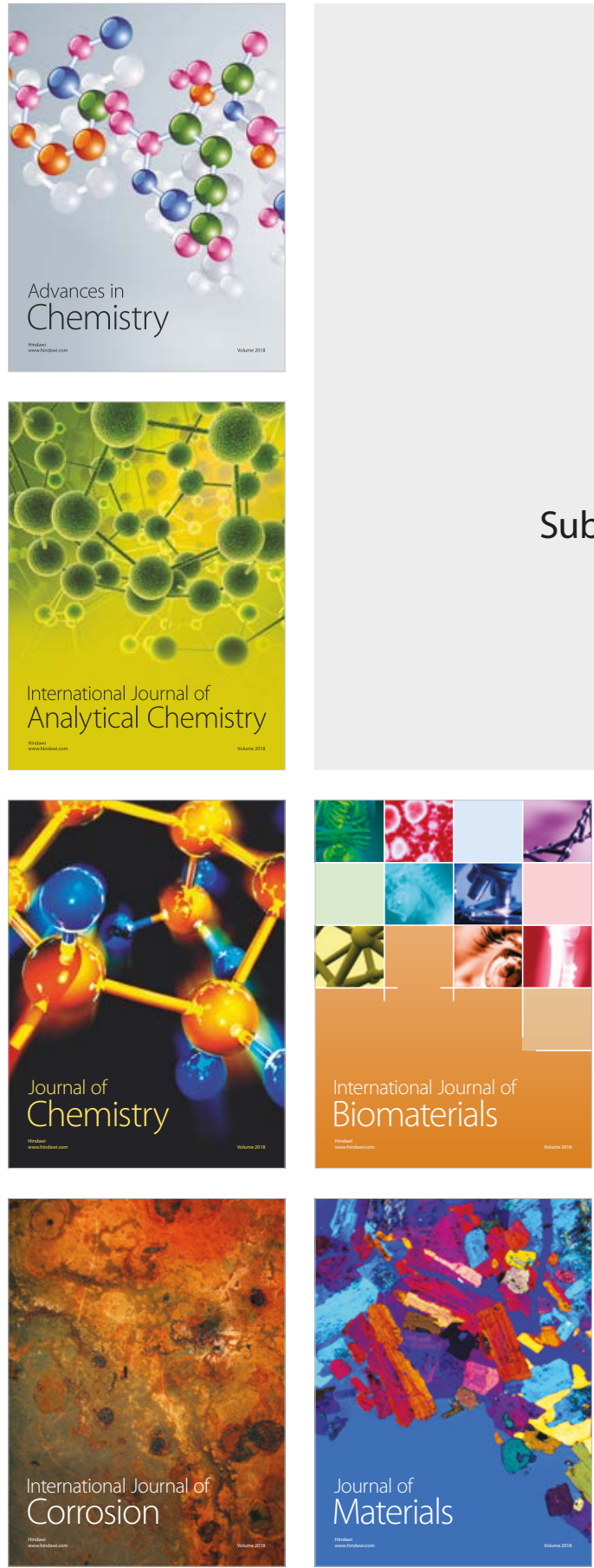

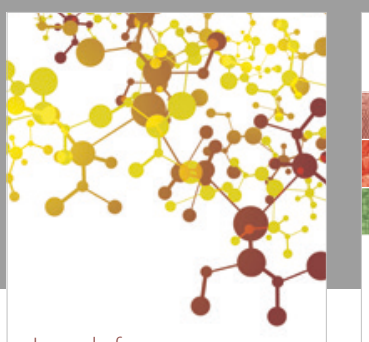

Journal of

Applied Chemistry
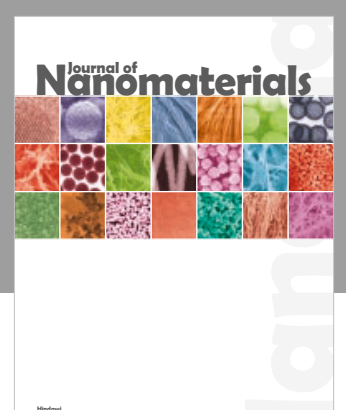

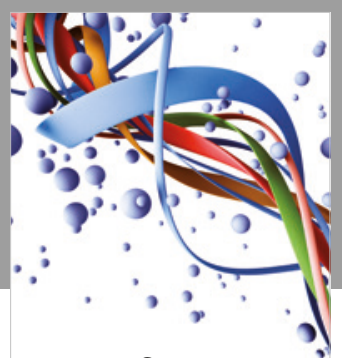

Scientifica

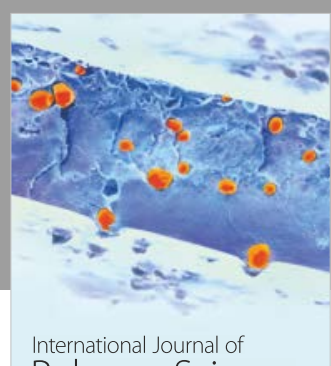

Polymer Science

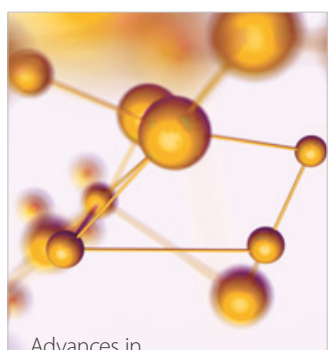

Physical Chemistry
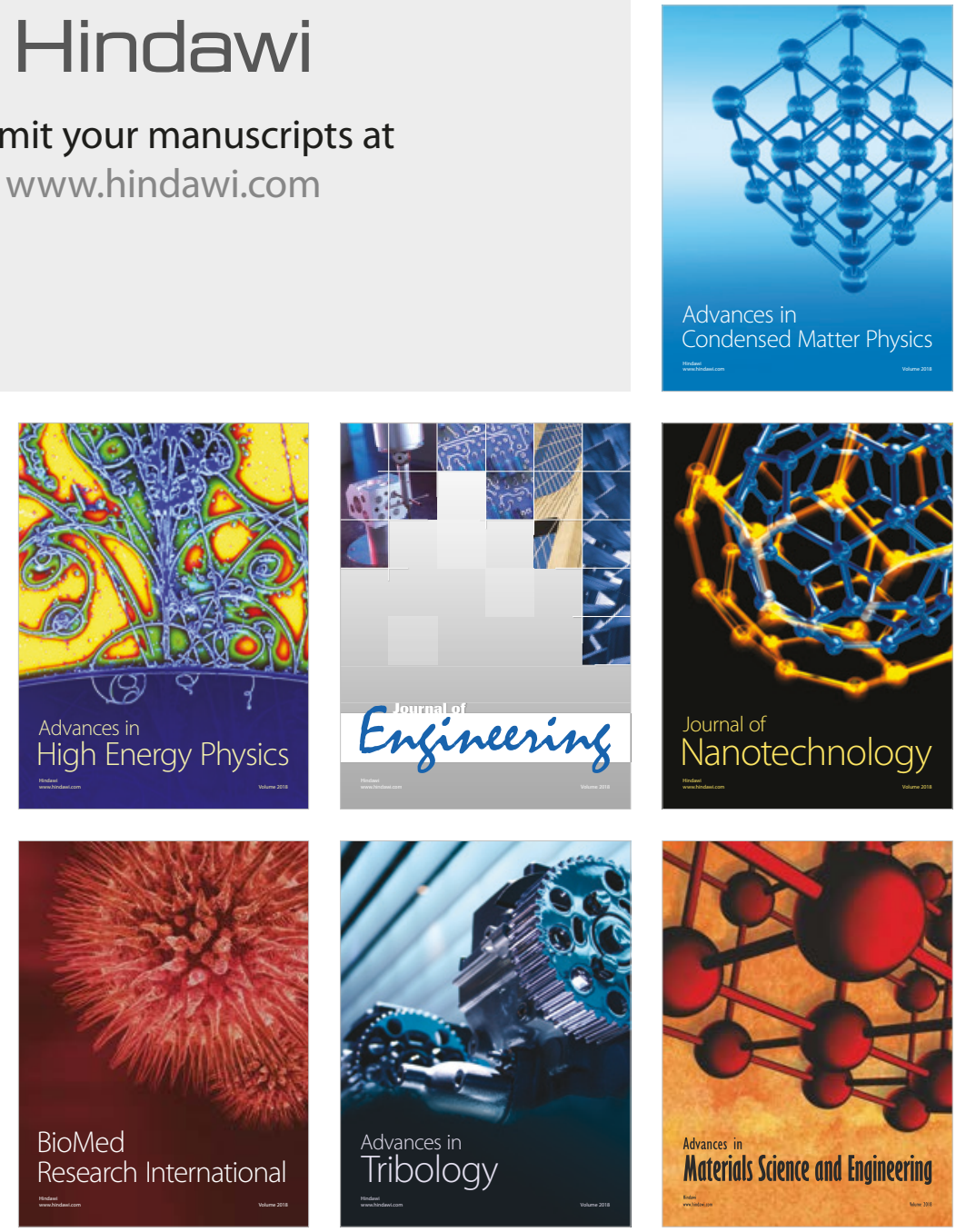